\title{
Fault model of the 2005 Fukuoka-ken Seiho-oki earthquake estimated from coseismic deformation observed by GPS and InSAR
}

\author{
Takuya Nishimura, Satoshi Fujiwara, Makoto Murakami, Hisashi Suito, Mikio Tobita, and Hiroshi Yarai
}

Geographical Survey Institute, Japan

(Received August 10, 2005; Revised September 26, 2005; Accepted September 30, 2005; Online published January 27, 2006)

\begin{abstract}
On 20 March 2005, the Fukuoka-ken Seiho-oki (the 2005 West off Fukuoka Prefecture) earthquake $\left(M_{\text {JMA }} 7.0\right)$ occurred in northern Kyushu, western Japan. We used coseismic deformation observed by GPS and InSAR to construct a fault model. The uniform slip model of rectangular dislocation in an elastic half-space suggests $\sim 1.4$ $\mathrm{m}$ of left-lateral strike slip faulting on a near-vertical fault. The fault strike is 298 degrees and its southeastern edge was strongly constrained by the displacement at a permanent GPS station located on Shikanoshima, which is consistent with the aftershock distribution. We estimated slip distribution on a planar fault and found the maximum slip of $\sim 1.9 \mathrm{~m}$ near the surface. Large slip is concentrated at depths of 0 to $10 \mathrm{~km}$ in an along-strike range from the hypocenter to $10 \mathrm{~km}$ east-southeast of it.
\end{abstract}

Key words: 2005 Fukuoka-ken Seiho-oki (West off Fukuoka Prefecture) earthquake, crustal deformation, GPS, InSAR, slip distribution.

\section{Introduction}

The 2005 Fukuoka-ken Seiho-oki (West off Fukuoka Prefecture) earthquake occurred north of Fukuoka City, northern Kyushu, western Japan on March 20, 2005 (Fig. 1) (e.g. Shimizu et al., 2006). The magnitude and hypocenter depth of the 2005 Fukuoka-ken Seiho-oki earthquake (hereafter Fukuoka earthquake) were 7.0 on the JMA (Japan Meteorological Agency) scale and $9 \mathrm{~km}$, respectively. Because the earthquake occurred close to the central part of Fukuoka City, whose population is 1.4 million, it caused about 1000 casualties and damaged many buildings. In Japan, permanent GPS stations of the GEONET are arrayed with an average spacing of 20-25 km (cf. Sagiya, 2004). The crustal deformation associated with the earthquake was detected by the GEONET. The Geographical Survey Institute (GSI) announced a preliminary note of coseismic displacement and a fault model of the earthquake 8 hours after the earthquake.

In this paper, we report coseismic displacement observed by continuous GPS including the GEONET and other networks. Campaign GPS measurement conducted by GSI and InSAR of ENVISAT data are used to map a detailed spatial pattern of the coseismic deformation. Finally, we construct a fault model estimated from the coseismic deformation.

\section{Coseismic Deformation}

\subsection{GPS}

Clear coseismic deformation associated with the Fukuoka earthquake was observed at GEONET stations in northern Kyushu. Figures 2 and 3 show the coseismic displacement at the permanent GPS stations with respect to 960668 (Hagi2) in Yamaguchi Prefecture. The

Copyright (c) The Society of Geomagnetism and Earth, Planetary and Space Sciences (SGEPSS); The Seismological Society of Japan; The Volcanological Society of Japan; The Geodetic Society of Japan; The Japanese Society for Planetary Sciences; TERRAPUB coseismic displacement at the reference station can be ignored because it is a long distance $(\sim 140 \mathrm{~km})$ from the hypocenter. The plotted coseismic displacement is the difference in the averages of daily solutions between March 10-19 and March 21-30. The daily solution used is the GEONET final (F2) solution obtained with Bernese GPS software version 4.2 (Rothatcher and Mervart, 2001) and IGS (International GNSS Service) final ephemeredes. We plotted the displacement at four permanent GPS stations (open circles in Fig. 1) in addition to those at the GEONET stations. Three GPS stations are for public surveying and are maintained by the GSI. The other is a DGPS station for differential GPS maintained by the Hydrographic and Oceanographic Department, Japan Coast Guard. These stations are equipped with dual-frequency receivers and the phase (RINEX) data can be downloaded through an anonymous FTP. We estimated the daily coordinate of these stations as well as of the GEONET stations using GIPSY-OASIS II software version 4.02 (Zumberge et al., 1997) to plot the displacement relative to one reference station. The coseismic displacement at these and the GEONET stations is based on the solution obtained using GIPSY and Bernese in Figs. 2 and 3. Using two software packages does not significantly affect the results, because the difference in the coseismic displacement estimated by them is less than $2 \mathrm{~mm}$ in horizontal components of the GEONET stations. The maximum horizontal displacement is $200 \mathrm{~mm}$ at 021062 on Shikanoshima located at the southern tip of the aftershock region (Fig. 2). In contrast to the horizontal displacement, which is significant at many stations in northern Kyushu, the vertical displacement is very small at most stations (Fig. 3). A significant subsidence of $37 \mathrm{~mm}$ was observed only at 021062 .

The tiltmeter equipped in the GPS pillar of 021062 recorded a $\sim 0.2$-degree tilt difference of the pillar after the 


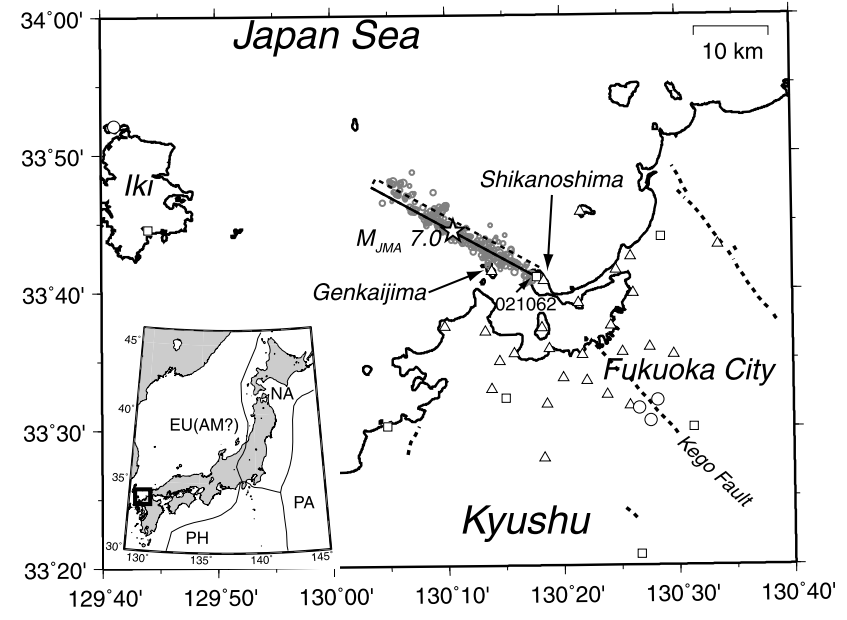

Fig. 1. Location map showing epicenters of the Fukuoka earthquake and its aftershocks and GPS stations. Open squares and circles represent the GEONET GPS stations and the other permanent GPS stations, respectively. Open triangles represent triangulation points observed by campaign GPS. A star and gray circles represent epicenters of the mainshock and aftershocks occurring on March 20, 2005, respectively. The dotted rectangle shows the fault location of the uniform slip model (See text). The solid line on the rectangles shows the upper edge of the fault. Thick dotted lines represent Quaternary faults (Active Fault Research Group, 1991). Abbreviations in tectonic map (inset) are NA, PA, PH, EU and AM for North America, Pacific, Philippine Sea, Eurasia, and Amurian plates, respectively. The rectangular area in tectonic map corresponds to the location map.

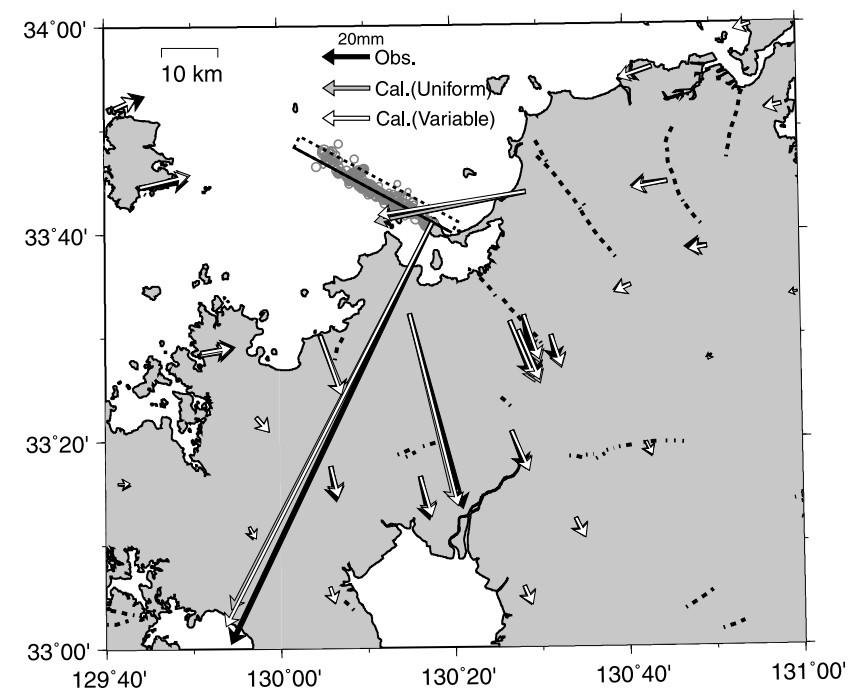

Fig. 2. Horizontal displacement of the Fukuoka earthquake at permanent GPS stations. White, gray, and black arrows represent observed displacements and calculated ones using the uniform slip and the variable slip models, respectively. The dotted rectangle shows the fault location of the variable slip model. The solid line on the rectangles shows the upper edge of the fault.

earthquake. This tilt difference is equivalent to $1.7 \mathrm{~cm}$ eastward displacement of the GPS antenna relative to the base of the pillar. The tilt difference should be caused by monument instability due to strong ground shaking. Onsite measurements by GSI staff members confirmed the tilt of the pillar. The displacement plotted in Fig. 2 is corrected for pillar tilting by subtracting the antenna displacement relative to the base. The tilt of the GEONET pillar caused by

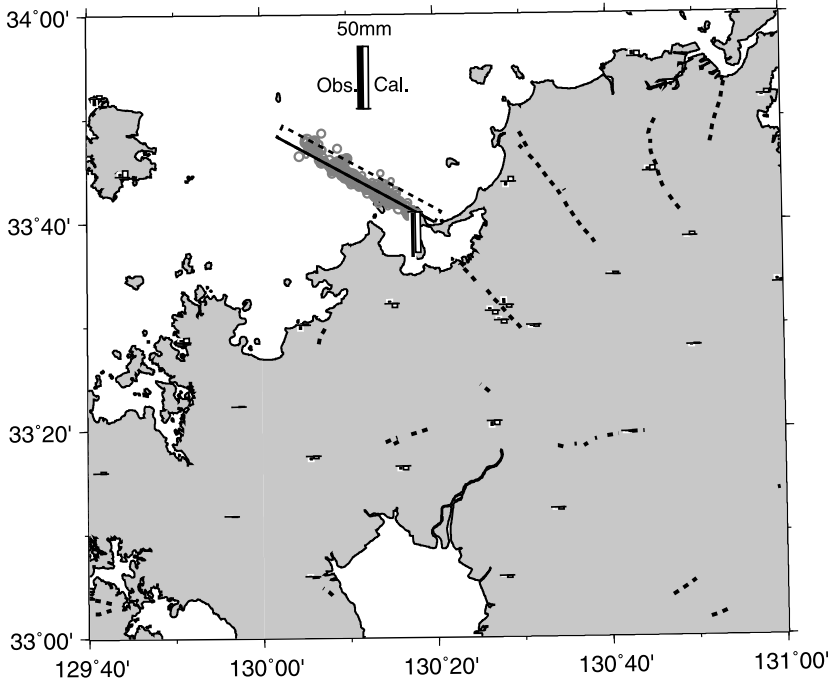

Fig. 3. Vertical displacement of the Fukuoka earthquake at permanent GPS stations. Open and solid bars represent observed and calculated displacements for the variable slip model, respectively.

strong shaking occurred at the time of the 2003 northern Miyagi earthquake (Nishimura et al., 2003).

GSI conducted urgent GPS measurements at 26 triangulation points near the epicenter just after the Fukuoka earthquake. Triangulation points maintained by GSI are stone benchmarks or metal plates. They are used as control points for all surveying carried out in Japan. The postseismic measurements were accomplished in the period of March 27 to 31, 2005. The preseismic measurements had been carried out at most points in 1994. Although the observation time for GPS measurements differs depending on the order of the triangulation points, it was longer than two hours. The difference between preseismic and postseismic coordinates is plotted in Fig. 4. The largest horizontal displacement was $\sim 380 \mathrm{~mm}$ on Genkaijima Island. Most points south of the epicentral areas moved southward and those east of the epicentral areas moved westward. The displacement in Fig. 4 includes not only the coseismic one of the Fukuoka earthquake but also interseismic movement that occurred during 1994-2005, and the error of centering the GPS antenna to a benchmark. Although the measurement accuracy of these points should be worse than that of the permanent GPS because of the short measurement time, the horizontal displacements in Fig. 4 have reasonable spatial correlations. Vertical displacements are also measured at the triangulation points. Large uplift of more than $100 \mathrm{~mm}$ was observed even at several points located $10 \mathrm{~km}$ south of the epicentral area. This is inconsistent with the data of the permanent GPS and InSAR, which will be discussed in the next section. It is well known that the accuracy of GPS measurements in vertical components is much worse than that in horizontal components. Therefore, we do not discuss vertical displacement at the triangulation points in detail.

\subsection{InSAR}

We used synthetic aperture radar (SAR) data acquired by ENVISAT of the European Space Agency. The SAR data taken on February 23 and March 30, 2005 were processed to generate an interferogram. The incident angle to 


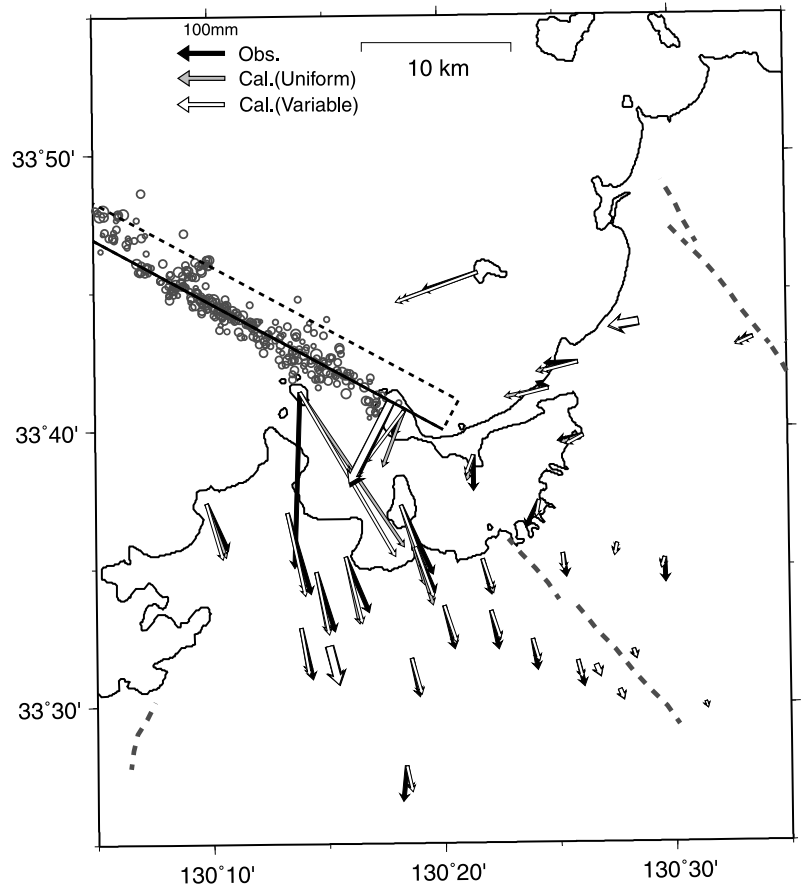

Fig. 4. Horizontal displacement at triangulation points and permanent GPS stations. White, gray, and black arrows represent observed displacements and calculated ones using the uniform slip and the variable slip models, respectively. Thick arrows mean displacement at the permanent GPS stations.

the satellite is 23 degrees. The satellite azimuth, that is, the angle between the satellite ground track and local north is 102 degrees. The interferogram in unwrapped form is shown in Fig. 5. The SAR interferogram represents the displacement in the line of sight (LOS) to the satellite. In this interferogram, we define that eastward and upward movements (range decrease between the ground and the satellite) increase the LOS displacement. Westward and downward movements (range increase) decrease the LOS displacement. A clear deformation signal is seen in the coherent part of the image. A positive displacement of 50 $\mathrm{mm}$ was recognized south of the epicenter. In contrast, a negative displacement of $50 \mathrm{~mm}$ was found east of the epicenter. We cannot obtain coherent images in mountainous areas and the Umi-no-nakamichi sandbar connecting Shikanoshima and Kyushu, where correlation between the preseismic and postseismic images is poor due to vegetation and strong ground motion of the earthquake.

\section{Modeling}

We invert the observed deformation to estimate the fault model. Because we have data observed by different methods, we must weigh the data for the inversion analysis. For the permanent GPS data, we calculated standard deviations of daily relative coordinates for every component and assigned them as data uncertainties. We doubled uncertainties for the 021262 station with the tilted pillar. The uncertainties are 1.1 to $5.4 \mathrm{~mm}$ for horizontal components and 4.3 to $15 \mathrm{~mm}$ for vertical components. The total number of permanent GPS stations used in the inversion is 39. Because there are no straightforward ways to assign uncertainties for campaign GPS and InSAR data, we assumed them arbitrarily. It

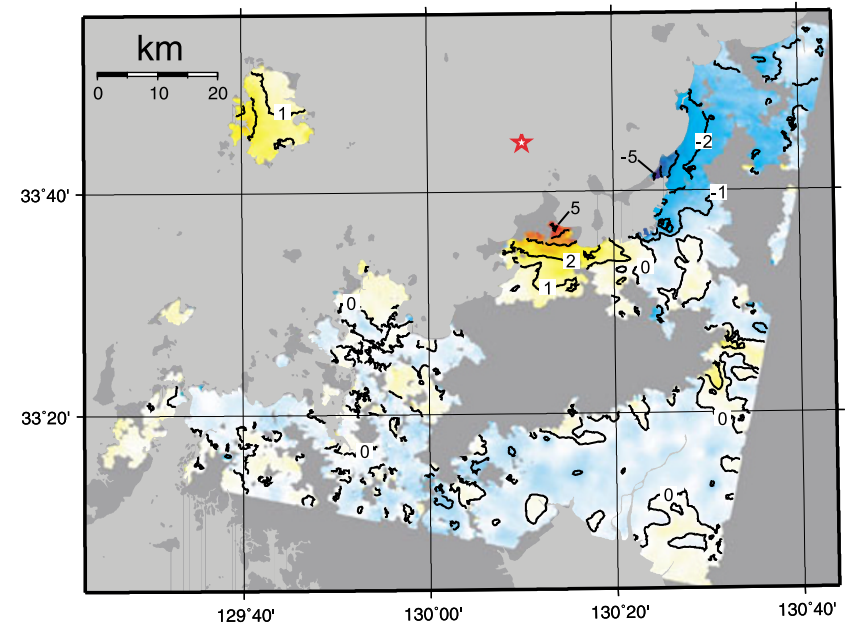

Fig. 5. Unwrapped interferogram showing the displacement in the line of sight (LOS) to the satellite. Red and blue indicate positive and negative LOS displacements with contour intervals of $1 \mathrm{~cm}$, respectively. Positive LOS displacements are towards the satellite. A star represents the epicenter of the Fukuoka earthquake.

is considered that uncertainties of campaign GPS are much worse because of the short measurement time, centering errors of GPS antennas, and long interval between pre- and postseismic measurements. We, therefore, assumed $50 \mathrm{~mm}$ for horizontal components and $100 \mathrm{~mm}$ for vertical components. For InSAR data, millions of data points exist in the interferogram. We reduced data points to 1518 points, as shown in Fig. 6 and assigned $30 \mathrm{~mm}$ as the data uncertainties. The total number of all data is 1635 .

For a first-order model, we start to estimate a rectangular fault model on which slip is uniform. We refer to it as the uniform slip model. The synthetic surface deformation is calculated using the formulation of Okada (1985) assuming a dislocation source in an elastic half-space. It is apparent that the fault is oriented in the direction west-northwest to east-southeast, as clearly shown by the aftershock distribution (Fig. 1). We used the nonlinear inversion method developed by Matsu'ura and Hasegawa (1987) to estimate parameters of a rectangular fault. In addition to solving for the fault parameters (e.g., location, depth, length, width, strike, dip, rake, and slip), we determine the offset in LOS displacement to account for ambiguities in the zero displacement level of the InSAR data. The estimated parameters are listed in Table 1. The focal mechanism is estimated in a left-lateral strike slip fault. Assuming the rigidity of $30 \mathrm{GPa}$, the seismic moment is $7.1 \times 10^{18} \mathrm{~N} \cdot \mathrm{m}\left(M_{\mathrm{w}} 6.5\right)$. The uniform slip model can explain the observed deformation reasonably well. The normalized residual (chi-square) is 211.7. The calculated horizontal displacement is compared with the observed one in Figs. 2 and 4. Large misfit in the direction of horizontal displacement is recognized only on Genkaijima Island (Fig. 4). Although the observed displacement is oriented towards the south, the calculated one is oriented east-southeast. It is notable that the eastern shallow tip of the fault is located just northwest of the 021062 station. Considering the depth and location of the fault, the distance between 021062 and the fault tip is only $\sim 90 \mathrm{~m}$. Because displacements near the tip of the rectangular fault 
(a)

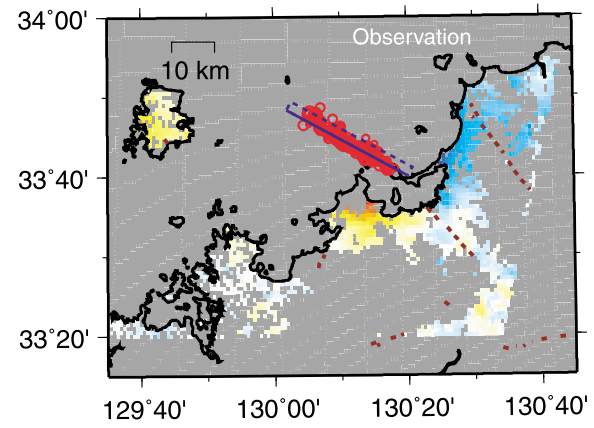

(b)

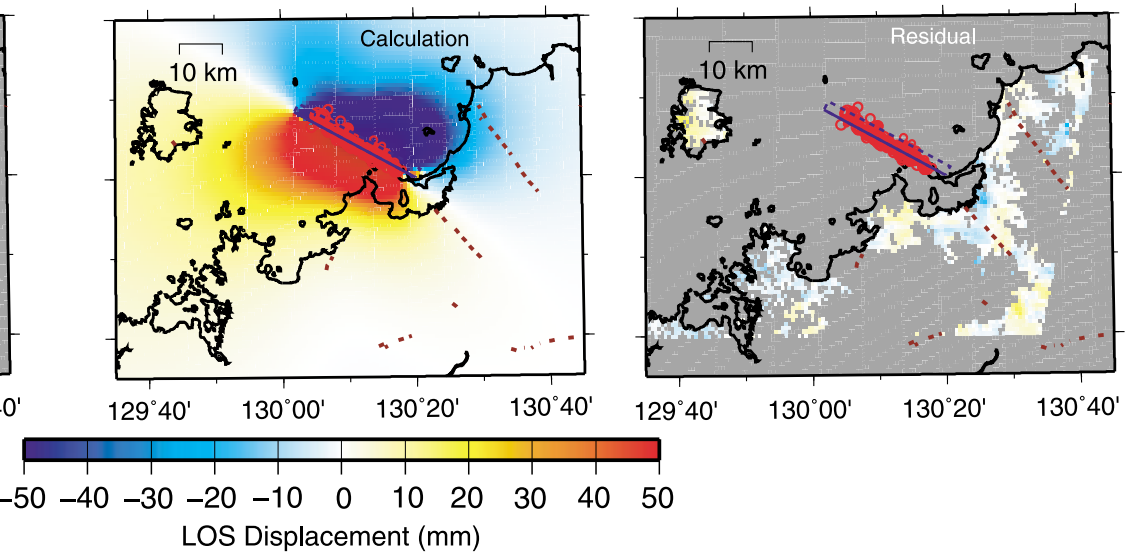

Fig. 6. (a) Observed interferogram after reducing the number of the data points. (b) Synthetic interferogram calculated using the variable slip model. (c) Residual interferogram of the synthetic interferogram subtracted from the observed one.

Table 1. Estimated fault parameters.

\begin{tabular}{ccccccccc}
\hline $\begin{array}{c}\text { Latitude* } \\
\left({ }^{\circ}\right)\end{array}$ & $\begin{array}{c}\text { Longitude* } \\
\left(^{\circ}\right)\end{array}$ & $\begin{array}{c}\text { Depth } \\
(\mathrm{km})\end{array}$ & $\begin{array}{c}\text { Length } \\
(\mathrm{km})\end{array}$ & $\begin{array}{c}\text { Width } \\
(\mathrm{km})\end{array}$ & $\begin{array}{c}\text { Strike } \\
\left({ }^{\circ}\right)\end{array}$ & $\begin{array}{c}\text { Dip } \\
\left({ }^{\circ}\right)\end{array}$ & $\begin{array}{c}\text { Rake } \\
\left({ }^{\circ}\right)\end{array}$ & $\begin{array}{c}\text { Slip } \\
(\mathrm{m})\end{array}$ \\
\hline 33.683 & 130.297 & 0.1 & 24.1 & 7.7 & 298 & 79 & 342 & 1.28 \\
\hline
\end{tabular}

*The coordinate system is Japanese Geodetic Datum 2000 (JGD2000).
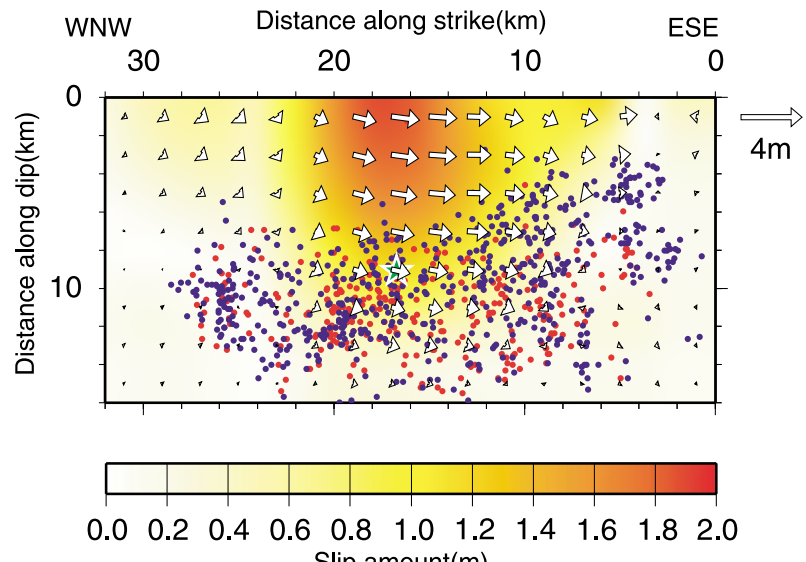

Slip amount(m)

Fig. 7. Fault slip distribution for the variable slip model of the Fukuoka earthquake. Arrows represent the movement of the hanging wall with respect to the footwall. A green star denotes the hypocenter of the mainshock projected on the fault plane. Red and blue dots denote the hypocenter of the aftershocks occurring on March 20 and March 21-29, respectively.

vary with space (Okada, 1985), the estimated location of the fault is strongly constrained by the displacement at 021062 . The fault location of the uniform slip model is shown in Fig. 1. The location and length of the fault corresponds to the aftershock area on March 20. The epicenter of the mainshock is located at the center of the fault, implying the rupture of the earthquake propagated bilaterally.

Next, we estimate the slip distribution on the fault plane. We defined the fault plane as the extension of the fault of the uniform slip model in the down-dip and along-strike directions. The length and width of the fault plane are 32 and
$16 \mathrm{~km}$, respectively. We divided the fault into $1282 \times 2$ $\mathrm{km}$ patches and estimated both strike and dip components of fault slip in each patch. To obtain a stable solution, we constrain smoothness of the fault slip and eliminate slip at the edges of the fault, except for the shallowest edge. The smoothness constraint is objectively determined by minimizing Akaike's Bayesian Information Criterion (ABIC) (Akaike, 1980). The result of slip distribution is shown in Fig. 7. As shown in Figs. 2-4 and 6, the variable slip model can explain all data well. We recognize large misfits at some triangulation points in Fig. 4. They may be attributed to large errors. The seismic moment for the variable slip model is $8.7 \times 10^{18} \mathrm{~N} \cdot \mathrm{m}\left(M_{\mathrm{w}} 6.6\right)$. A normalized residual (chi-square) is 168.9 .

\section{Discussion}

We here discuss the characteristics of the slip distribution in the variable slip model. A peak of slip amounting to 1.86 $\mathrm{m}$ is located on the shallowest patch in the middle of the fault (Fig. 7). Large slip in a very shallow part suggests that a surface rupture may have occurred on the seafloor for the Fukuoka earthquake, although any evidence of a surface rupture were not found by sea floor surveys (Japan Coast Guard, 2005). A large slip area ranges from 10 to $20 \mathrm{~km}$ along the strike and 0 to $10 \mathrm{~km}$ along the dip on the fault. The feature of a large slip area located east and up-dip of the hypocenter of the mainshock is roughly concordant with the results estimated from seismic waveform inversion (e.g. Yamanaka, 2005; Asano and Iwata, 2006; Kobayashi et al., 2006). The shallowest patch from 4 to $6 \mathrm{~km}$ along the strike has a local peak of slip amounting to $1.12 \mathrm{~m}$. The slip of this patch is constrained by displacement at the 021062 station. Large slip near that station are also found 
by the waveform inversion using $1-\mathrm{Hz}$ sampling kinematic GPS and accelerometers (Kobayashi et al., 2006). The slip distribution suggests that the rupture propagation of the Fukuoka earthquake stopped there because patches from 0 to $4 \mathrm{~km}$ along the strike have very small slip. We plotted aftershocks projected onto the fault plane in Fig. 7. Most aftershocks, as well as the mainshock, are located beneath an area of large coseismic slip. The aftershocks became active in the area of 3 to $10 \mathrm{~km}$ along the strike and 4 to $10 \mathrm{~km}$ along the dip after March 21. They occurred around the edge of the large-slip area. This implies that they were triggered by a stress change of the coseismic slip including afterslip and aftershocks just after the mainshock.

The aftershock distribution (Fig. 4) suggests that the fault of the Fukuoka earthquake branches at some points and bends at both ends. The fault plane estimated in this study is $\sim 1 \mathrm{~km}$ north of the main alignment of aftershocks. This offset is significantly larger than the uncertainties of the estimated parameters and the hypocenter determinations of the earthquakes. Under the assumption of a single planar fault and an elastic half-space, the location of the estimated fault is greatly constrained by the displacement at 021062 . We suspect that the observation point is so close to the fault that the assumption may be incorrect. In addition, numerous fissures and landslides were found in the vicinity of 021062 on Shikanoshima though no surface rupture directly related with earthquake faulting was ever found (Toda et al., 2005). The displacement observed at the 021062 station may contaminate such a local effect. Ito et al. (2006) estimated the focal mechanism of the mainshock by using the centroid moment tensor inversion and polarities of $P$-wave initial phases. They concluded that a fault strike differs in the northern part where the rupture started and the central part where a large seismic moment was released. Considering a complex geometry that includes fault branching, bending, and heterogeneity of the medium is a task left for the future.

From the viewpoint of earthquake hazards, it is important whether the Fukuoka earthquake is related to the Kego fault crossing the densely populated area of Fukuoka City (Fig. 1). The fault of the Fukuoka earthquake is on an extension of the Kego fault, though their strike directions are slightly different. Our result shows that the coseismic slip stopped north of Shikanoshima and that the Fukuoka earthquake did not rupture south of Shikanoshima. There are no significant signals of the residual interferogram near the Kego fault (Fig. 6(c)). Therefore, we found neither coseismic nor aseismic slip on the Kego fault from the geodetic data. However, we should pay attention to the stress increase on the Kego fault caused by the Fukuoka earthquake (Toda and Horikawa, 2005; GSI, 2005). Compared with other parts of Japan, the epicentral area and its vicinities historically have very low activity of large earthquakes and recent microseismicity. The preseismic strain rate in northern Kyushu, including the epicentral area, is much lower than the average for the Japanese islands according to the GEONET (GSI, 2005). In such a tectonic situation, the stress disturbance by the earthquakes may be more important than that in tectonic active regions (Toda et al., 1998). In addition, the largest aftershock $\left(M_{\mathrm{JMA}} 5.8\right)$ occurred at the deep and southeast edge of the coseismic slip area on April
20. The postseismic deformation around the southeastern end of the coseismic fault is important to consider a further crustal activity.

\section{Conclusion}

The coseismic displacements of the 2005 Fukuoka-ken Seiho-oki earthquake were observed by continuous GPS, campaign GPS, and InSAR. The GEONET 021062 station has a maximum horizontal displacement of $200 \mathrm{~mm}$ and a subsidence of $37 \mathrm{~mm}$. Campaign GPS measurements show that a triangulation point on Genkaijima Island moved southward by $370 \mathrm{~mm}$. Peak-to-peak LOS displacement of $100 \mathrm{~mm}$ was detected by InSAR. The moment magnitude estimated from the geodetic data is $M_{\mathrm{w}} 6.6$. The slip distribution shows that an area of large slip is located at a shallow depth east of the hypocenter. That the maximum slip of $1.9 \mathrm{~m}$ occurred in the shallowest patch may suggest surface rupture for this earthquake on the seafloor.

Acknowledgments. We thank members of Research Planning Div., Satellite Geodesy Div., Geodetic Reference Div., Mobile Observation Div., Kyushu Regional Survey Dept. of the Geographical Survey Institute for providing the data and the information on the observation points. Comments by Prof. K. Hirahara and an anonymous reviewer improved the manuscript. The hypocenter data were provided by the Japan Meteorological Agency in cooperation with the Ministry of Education, Culture, Sports, Science, and Technology. We used GPS data provided by the Hydrographic and Oceanographic Department, the Japan Coast Guard. Figures were generated using the GMT (Generic Mapping Tool) package by Paul Wessel and Walter H. F. Smith.

\section{References}

Active Fault Research Group, Active Faults in Japan: sheet maps and inventories (Revised ed.), 437 pp., University of Tokyo Press, Tokyo, 1991 (in Japanese).

Akaike, H., Likelihood and the Bayes procedure, in Bayesian Statistics, edited by J. M. Bernardo, M. H. DeGroot, D. V. Lindley, and A. F. M. Smith, pp. 143-166, University Press, Valencia, 1980.

Asano, K. and T. Iwata, Source process and near-source ground motions of the 2005 West Off Fukuoka Prefecture earthquake, Earth Planets Space, 58, this issue, 93-98, 2006.

Geographical Survey Institute, Crustal Movements in the Chugoku, Shikoku, and Kyushu Districts (in Japanese), Rep. coordinating committee for earthquake prediction, 74, 408-439, 2005.

Ito, Y., K. Obara, T. Takeda, K. Shiomi, T. Matsumoto, S. Sekiguchi, and S. Hori, Initial-rupture fault, main-shock fault, and aftershock faults: Fault geometry and bends inferred from centroid moment tensor inversion of the 2005 west off Fukuoka prefecture earthquake, Earth Planets Space, 58, this issue, 69-74, 2006.

Japan Coast Guard, Investigation on the seafloor around the source area of the 2005 West off Fukuoka prefecture earthquake, http:// www1.kaiho.mlit.go.jp/KAIYO/FAULTS/fukuoka/fukuokaWest_C.pdf, 2005 (in Japanese).

Kobayashi, R., S. Miyazaki, and K. Koketsu, Source processes of the 2005 West Off Fukuoka Prefecture earthquake and its largest aftershock inferred from strong motion and 1-Hz GPS data, Earth Planets Space, 58, this issue, 57-62, 2006.

Matsu'ura, M. and Y. Hasegawa, A maximum likelihood approach to nonlinear inversion under constraints, Phys. Earth Planet. Inter., 47, 179187, 1987.

Nishimura, T., T. Imakiire, H. Yarai, T. Ozawa,. M. Murakami, and M. Kaidzu, A preliminary fault model of the 2003 July 26, M6.4 northern Miyagi earthquake, northern Japan, estimated from joint inversion of GPS, leveling, and InSAR data, Earth Planets Space, 55, 751-757, 2003.

Okada, Y., Surface deformation due to shear and tensile faults in a halfspace, Bull. Seismol. Soc. Am., 75, 1135-1154, 1985.

Rothacher, M. and L. Mervart, Bernese GPS Software Version 4.2 documentation, Astronomical Institute, University of Berne, 2001. 
Sagiya, T., A decade of GEONET:1994-2003-The continuous GPS observation in Japan and its impact on earthquake studies, Earth Planets Space, 56, xxix-xli, 2004.

Shimizu, H., H. Takahashi, T. Okada, T. Kanazawa, Y. Iio, H. Miyamachi, T. Matsushima, M. Ichiyanagi, N. Uchida, T. Iwasaki, H. Katao, K. Goto, S. Matsumoto, N. Hirata, S. Nakao, K. Uehira, M. Shinohara, H. Yakiwara, N. Kame, T, Urabe, N. Matsuwo, T. Yamada, A. Watanabe, K, Nakahigashi, B. Enescu, K. Uchida, S, Hashimoto, S. Hirano, T. Yagi, Y. Kohno, T, Ueno, M. Saito, and M. Hori, Urgent joint observation of the 2005 West off Fukuoka Prefecture earthquake, Earth Planets Space, 2006 (to be submitted).

Toda, S. and H. Horikawa, Stress transferred by the M 7.0 Fukuokaken-seiho-oki earthquake: Influence on the Kego fault beneath the city of Fukuoka, Abstracts 2005 Japan Earth and Planetary Science Joint Meeting, X113-P025, 2005.

Toda, S., R. S. Stein, P. A. Reasenberg, J. H. Dieterich, and A. Yoshida,
Stress transferred by the $\mathrm{Mw}=6.9$ Kobe, Japan, shock: Effect on aftershocks and future earthquake probabilities, J. Geophys. Res., 103 24543-24565, 1998.

Toda, S., T. Azuma, Y. Miyashita, and H, Kondo, Investigation on Surface deformation associated with the set off Fukuoka Prefecture earthquake, http://unit.aist.go.jp/actfault/fukuoka/hokoku/index.html, 2005 (in Japanese).

Yamanaka, Y., Source process of the west off Fukuoka Prefecture earthquake, EIC Seismological Note: No. 163, 2005.

Zumberge, J. F., M. B. Heflin, D. C. Jefferson, M. M. Watkins, and F. H. Webb, Precise point positioning for the efficient and robust analysis of GPS data from large network, J. Geophys. Res., 102, 5005-5017, 1997.

T. Nishimura (e-mail: t_nisimura@gsi.go.jp), S. Fujiwara, M. Murakami, H. Suito, M. Tobita, and H. Yarai 